\title{
Estudo comparativo do tingimento de malha PES/CO com água tratada com resíduo de clarificação de óleo vegetal, na forma natural e calcinada
}

\author{
Comparative study of PES/CO knitted \\ fabrics dyeing with water treated with \\ vegetable oil clarification residue, \\ in natural and calcined form
}

Ivonete Oliveira Barcellos ${ }^{1}$, Taciane Samira Dalle Cort ${ }^{1}$

\begin{abstract}
${ }^{1}$ Departamento de Química - Universidade Regional de Blumenau- FURB, CEP: 89030-903, Blumenau, Santa Catarina, Brasil.e-mail: iob@furb.br, tacisdct@hotmail.com
\end{abstract}

\section{RESUMO}

A indústria têxtil utiliza um grande volume de água, o que torna necessário encontrar opções mais sustentáveis para o seu uso, como a reutilização em novos tingimentos. O uso de um resíduo industrial sólido, como adsorvente, poderá ser uma alternativa para tratar o efluente têxtil. Este estudo teve como objetivo testar a viabilidade do reuso de solução de corante disperso, tratada com resíduo da clarificação de óleo vegetal como adsorvente alternativo, no tingimento de malha poliéster/algodão (PES/CO 50/50). Utilizou-se dois tipos de pré-tratamento no adsorvente, natural (RC) seco a $70^{\circ} \mathrm{C}$ por $24 \mathrm{~h}$ e calcinado $(\mathrm{RCc})$ a $600^{\circ} \mathrm{C}$ por $2 \mathrm{~h} 30 \mathrm{~min}$. Realizou-se o tingimento na cor clara com a solução tratada nas concentrações $100 \%$, 75\% e 50\% (v/v), o padrão foi tinto com água da indústria têxtil. Para análise da eficiência do tratamento utilizou-se espectrofotometria UV-Vis, e a avaliação dos tecidos tintos pelos parâmetros tintoriais: esgotamento (\%) por espectrofotometria UV-Vis; K/S, força relativa (FR\%) e DE por espectrofotometria de remissão, como também ensaios de solidez a fricção e a lavagem. A eficiência do tratamento foi de 91,26\% para o resíduo RC, e 95,38\% para o RCc. Os valores de esgotamento variaram entre $80 \%$ e $92 \%$ para PES e $70 \%$ e $85 \%$ para CO. O DE variou entre 0,22 e 1,2, sendo que a maioria dos valores estão dentro da faixa aceita pela indústria $(\mathrm{DE} \leq 1,0)$. Não houve grande variação para os valores de K/S e a FR (\%), tendo a maior variação de 0,09 unidades para o K/S e 7,2\% para a FR (\%). Os testes de solidez apresentaram notas entre 4/5 e 5 nas escalas de cinza, indicando que não há a migração do corante. A proposta do tratamento e reutilização da solução em novos tingimentos mostrou-se uma alternativa viável, quando comparado ao tingimento padrão.

Palavras-chave: Poliéster, Algodão, Fibras, Adsorção, Corante.

\section{ABSTRACT}

The textile industry uses a large volume of water, which makes it necessary to find more sustainable options for its use, such as reuse in new dyeing. The use of a solid industrial waste as an adsorbent may be an alternative to treat the textile effluent. The objective of this study was to test the viability of the reuse of dispersed dye solution, treated with residue of the clarification of vegetable oil as an alternative adsorbent, in polyester/cotton (PES/CO 50/50) knitted fabrics dyeing. Two types of pre-treatment were used in the adsorbent, natural (RC) dried at $70^{\circ} \mathrm{C}$ for $24 \mathrm{~h}$ and calcined $(\mathrm{RCc})$ at $600^{\circ} \mathrm{C}$ for $2 \mathrm{~h} 30 \mathrm{~min}$. Dyeing was performed with the solution treated at $100 \%, 75 \%$ and $50 \%(\mathrm{v} / \mathrm{v})$ concentrations and in light colors, the pattern was dyed with water from the textile industry. UV-Vis spectrophotometry was used to evaluate the efficiency of the treatment and the evaluation of the red tissues by dyeing parameters: exhaustion (\%) by UV-Vis spectrophotometry; K/S, relative strength (SR\%) and DE by remission spectrophotometry, as well as color fastness to washing and friction. The treatment efficiency was $91,26 \%$ for RC residue, and $95,38 \%$ for RCc. Values ranged from $80 \%$ to $92 \%$ for PES and $70 \%$ to $85 \%$ for CO. The DE ranged from 0,22 to 1,2 , with most values falling into the range accepted by industry $(\mathrm{DE} \leq 1,0)$. There was no great variation for $\mathrm{K} / \mathrm{S}$ and $\mathrm{SR}(\%)$ values, with the greatest variation of 0,09 units for K/S and 7,2\% for SR (\%). The color fastness showed grades between $4 / 5$ and 5 on the gray scales, indicating that there is no migration of the dye. The proposal of treatment and reuse of the solution in new dyeing showed as a viable alternative when compared to the standard dyeing. 
Keywords: Polyester, Cotton, Fibers, Adsorption, Dye.

\section{INTRODUÇÃO}

O setor têxtil possui grande importância na economia brasileira, somando 31,9 mil indústrias e 1,6 milhão de empregos no país, isso no ano de 2014 [1,2]. Sendo assim, o setor têxtil é um dos maiores produtores de efluentes líquidos, visto a grande demanda de utilização de água para processos, especialmente na área de beneficiamento têxtil, em artigos de poliéster (PES) e algodão (CO), bem como mesclas destes tecidos. Estudos têm sido realizados visando melhorias no rendimento colorístico e/ou funcionalidade no beneficiamento [3].

Esse efluente proveniente das atividades têxteis gera grande preocupação, devido à sua alta toxicidade, e ao fato de bloquearem a luz, devido sua coloração, causando danos à vida aquática, e se descartado de forma incorreta pode ocasionar danos à saúde e ao meio ambiente [4,5].

Neste conceito de sustentabilidade, alternativas estão sendo estudadas, pensando na crise global da água, desde desenvolvimento de um novo produto até o produto final manufaturado, incluindo reciclagem de materiais. Na incansável busca pela sustentabilidade, torna-se necessário o desenvolvimento de novos métodos para tratamento de efluentes têxteis, uma vez que a eficiência dos métodos utilizados para a remoção dos corantes nem sempre alcançam os índices estabelecidos pelas agências de regularização, ou que possibilitem o reuso da água [6].

A adsorção tem sido amplamente estudada como forma alternativa para a remoção de corantes têxteis em soluções e efluentes, sendo uma técnica de grande interesse pelo baixo custo e elevada eficiência, possibilidade de recuperação da água tratada, bem como do corante adsorvido, sem gerar subprodutos [7].

Diferentes adsorventes alternativos têm sido estudados para o tratamento de efluentes/soluções de corantes, como pode ser observado na tabela 1, que traz uma relação de alguns trabalhos desenvolvidos com a técnica de adsorção e relaciona o adsorvente com o adsorbato, bem como sua eficiência de remoção do corante.

Tabela 1: Eficiência de remoção de corantes em diversos adsorvente.

\begin{tabular}{|c|c|c|c|}
\hline ADSORVENTE & ADSORBATO & $\begin{array}{l}\text { EFICIÊNCIA } \\
(\%)\end{array}$ & $\begin{array}{l}\text { REFERÊNCIA, AUTOR, } \\
\text { DATA }\end{array}$ \\
\hline Bagaço de maçã & Reactive Blue 203 e Red 195 & 95 & [8] Marin, 2015 \\
\hline Carvão de casca de pequi & Azul de Metileno & 68 & [9] Patias, 2015 \\
\hline Cinza de casca de arroz & $\begin{array}{l}\text { Amarelo procion HEXL e } \\
\text { Azul procion HEXL }\end{array}$ & 93,3 & [7] Wilhelm, 2016 \\
\hline Saccharomyces cerevisiae & Direct Orange 2GL & 96 & [10] Mendes, 2015 \\
\hline Cerâmica vermelha & Direct Blue & 98,2 à 99,5 & [11] Silva, 2017 \\
\hline Argila esmectíticas & Rodamina B & $\geq 90$ & [12] Duarte-Neto, 2014 \\
\hline Fibras de milho e cascas de Luffa & $\begin{array}{l}\text { Azul de metileno, Azul de Alcian, } \\
\text { Vermelho neutro, Azul brilhante }\end{array}$ & $\geq 90$ & [13] Mallampati, 2015 \\
\hline Resíduo de café & $\begin{array}{l}\text { Remazol Brillant Blue RN, Basic } \\
\text { Blue 3G }\end{array}$ & $80-90$ e $50-60$ & [14] Kyzas, 2012 \\
\hline \multirow{2}{*}{$\begin{array}{l}\text { Resíduo de clarificação de óleo vege- } \\
\text { tal natural e termicamente tratado }\end{array}$} & Direto Preto 22 & 86,8 e 95,7 & [15] Mittersteiner, 2017 \\
\hline & Rubi Colorsperse S-EGFL & 95,8 e 96,2 & [16] Müller, 2017 \\
\hline
\end{tabular}

A tabela 1, mostra alguns estudos utilizando resíduos como adsorvente, alternativos ao carvão ativado, como por exemplo, o resíduo de clarificação de óleo vegetal, o mesmo adsorvente utilizado neste trabalho. $\mathrm{O}$ uso de adsorventes residuais, naturais ou sintéticos, é altamente promissor, pois além dos benefícios da adsorção já citados, possibilita um destino adequado para os resíduos líquidos (efluente) e sólidos simultaneamente [16].

O resíduo de clarificação de óleo vegetal é um resíduo da indústria alimentícia gerado em grande escala, com estimativa em torno de 2 milhões de toneladas por ano no mundo [17]. O destino mais comum e barato para esse resíduo foi por muito tempo os aterros sanitários, porém por mudanças na legislação existe restrição a esse tipo de descarte, por diversos motivos, como, autoignição, lixiviação e contaminação de lençóis freáticos $[16,18]$. Por esses motivos é de extrema importância que encontrem-se novos usos e destinos para esse tipo de resíduo.

O objetivo deste estudo foi comparar o tingimento de malha poliéster/ algodão (PES/CO) ao reutilizar uma solução de corante disperso pós tratamento por adsorção com resíduos de clarificação de óleo vegetal 
(RC) na forma natural e calcinada, levantando dados para estudos futuros de reutilização de água na indústria têxtil.

\section{MATERIAIS E MÉTODOS}

\subsection{Preparo do adsorvente RC e RCc da solução de corante para tratamento}

Para o tratamento da solução de corante, utilizou-se o resíduo industrial da clarificação de óleo vegetal em diferentes condições, na forma natural e calcinada (figura 1). O resíduo natural (RC) foi seco em estufa a $70^{\circ} \mathrm{C}$ por $24 \mathrm{~h}$ e passado em peneiras granulométricas para padronizar a granulometria em $\leq 250 \mu \mathrm{m}$, após esse procedimento secou-se novamente em estufa $\left(70^{\circ} \mathrm{C} / 24 \mathrm{~h}\right)$. O resíduo calcinado $(\mathrm{RCc})$ foi incinerado a $600^{\circ} \mathrm{C}$ por $2 \mathrm{~h}$ e $30 \mathrm{~min}$ em mufla Fornos Lavoisier 400C. Após a incineração, passou-se o material em peneiras granulométricas para verificar a granulometria resultante do processo, sendo que este encontra-se com granulometria $\leq 45 \mu \mathrm{m}$, estes resíduos foram utilizados no tratamento das soluções de corante disperso por adsorção.

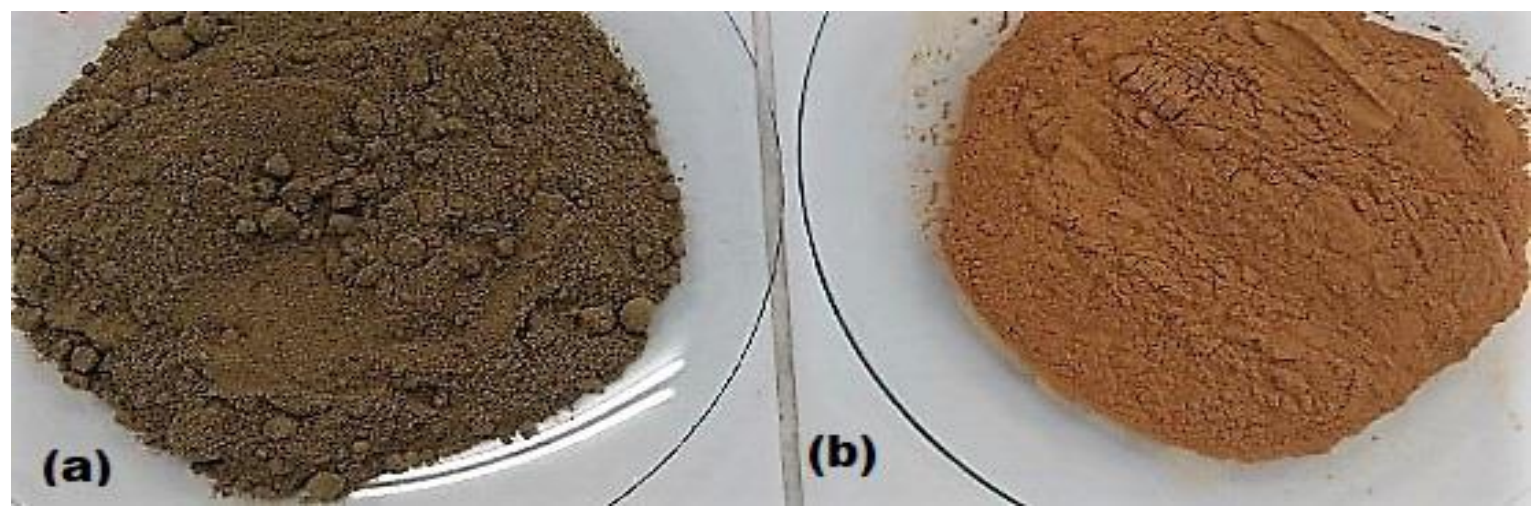

Figura 1: Diferentes preparações do resíduo de clarificação $\mathrm{RC} \leq 250 \mu \mathrm{m}$ (a) e $\mathrm{RCc} \leq 45 \mu \mathrm{m}$ (b).

\subsection{Tratamento da solução de corante disperso Rubi colorpes S-EGFL}

Para o tratamento por adsorção preparou-se uma solução do corante Rubi na concentração de $0,1 \mathrm{~g} . \mathrm{L}^{-1}$. Para a adsorção utilizou-se $2 \mathrm{~g}$ do adsorvente RC em $50 \mathrm{~mL}$ de solução, e $1 \mathrm{~g}$ do RCc em $50 \mathrm{~mL}$ de solução. O tratamento por adsorção foi realizado em banho termostatizado com agitação orbital - Tipo Dubnoff, modelo 093, Tecnal, a $40^{\circ} \mathrm{C}$ por $24 \mathrm{~h}$ com rotação permanente de $130 \mathrm{rpm}$, de acordo com literatura [16].

\subsection{Eficiência do tratamento da solução de corante}

A eficiência (E \%) do tratamento, ou seja, o percentual de remoção do corante da solução foi determinado empregando-se os dados obtidos de absorbância, no comprimento de onda de máxima absorção do corante (477nm ou 498nm), pela técnica de espectrofotometria UV-Vis, no equipamento Espectrofotômetro UV-Vis Shimadzu UV-1800, e com os dados obtidos calculou-se o percentual de remoção do corante através da equação 1.

$$
E(\%)=\frac{A b s .(\lambda \max ) \text { inicial }- \text { Abs. }(\lambda \max ) \text { final }}{A b s .(\lambda \max ) \text { inicial }} \times 100
$$

Onde: Abs. $(\lambda \max )$ inicial= absorbância antes do tratamento $(477 \mathrm{~nm}$ ou $498 \mathrm{~nm})$.

Abs. $(\lambda \max )$ final= absorbância final do tratamento $(477 \mathrm{~nm}$ ou $498 \mathrm{~nm})$.

\subsection{Tingimento de malha PES/CO utilizando água tratada}

Após o tratamento por adsorção da solução de corante Disperso Rubi Colorpes S-EGFL 250\%, a mesma foi utilizada em tingimentos de malha PES/CO, com gramatura $182,7 \mathrm{~g} / \mathrm{m}^{2}$, pré-alvejada.

Foram utilizadas diferentes quantidades de água tratada nos tingimentos, sendo $100 \%, 75 \%$ e $50 \%$ (v/v), completando com água industrial, utilizada nos tingimentos da empresa Trama Z. Para uma posterior avaliação e comparação do tingimento utilizando água tratada com resíduo natural e calcinado foi tinta uma 
cor clara. A receita de tingimento utilizada está representada na tabela 2. Optou-se pelo tingimento de uma cor clara, uma vez que tonalidades claras sofrem maiores desvios de tonalidade quando sujeitas à pequenas alterações nas condições de tingimento. Para efeito de comparação tingiu-se nas mesmas condições, utilizando $100 \%$ de água industrial, como padrão.

Tabela 2: Receita de corantes e auxiliares para o tingimento de cor clara

\begin{tabular}{|c|c|c|c|}
\hline $\begin{array}{l}\text { CORANTE DISPERSO VERMELHO } \\
\text { SIDERSPERSE BE2B (\%) }{ }^{a}\end{array}$ & $\begin{array}{l}\text { AUXILIARES } \\
\text { POLIÉSTER }\end{array}$ & $\begin{array}{l}\text { CORANTE REATIVO VERMELHO } \\
\text { SIDERCRON HC (\%) }\end{array}$ & $\begin{array}{l}\text { AUXILIARES } \\
\text { ALGODÃO }\end{array}$ \\
\hline 0,1 & $\begin{array}{l}\text { D-Cor } 2 \text { g.L } \mathrm{L}^{-1} \\
\text { RPL } 2 \text { g.L } \mathrm{L}^{-1}\end{array}$ & 0,08 & $\begin{array}{l}\text { D-Cor } 1 \text { g.. } \mathrm{L}^{-1} \\
\text { CS } 1 \text { g. } \mathrm{L}^{-1} \\
\text { Sal } 10 \text { g. } \mathrm{L}^{-1} \\
\text { Barrilha } 10 \text { g.L } \mathrm{L}^{-1}\end{array}$ \\
\hline
\end{tabular}

${ }^{\mathrm{a}}$ sobre massa do material (substrato têxtil).

Para o tingimento da malha de PES/CO dividiu-se o processo em duas etapas, a primeira sendo o tingimento da fibra de poliéster (PES) e a segunda parte o tingimento da fibra de algodão (CO). $\mathrm{O}$ tingimento de poliéster foi realizado em máquina de tingimento $\mathrm{HT}$ Infrared a $135^{\circ} \mathrm{C}$ por 30 minutos, em seguida realizouse um enxágue e centrifugação desta malha. Então na segunda etapa tingiu-se o algodão, em máquina Tubotest a $85^{\circ} \mathrm{C}$ por 50 minutos. Após o tingimento foi realizada uma lavação, com água industrial, com ácido acético para neutralizar as bases, utilizadas durante o tingimento do algodão, e posteriormente uma lavação, com água industrial, a $95^{\circ} \mathrm{C}$ por 15 minutos com sabão neutro, em máquina HT Infrared, para remover todo o corante não fixado na fibra, então fez-se a secagem. Para a obtenção de um controle a amostra padrão foi tinta com $100 \%$ de água industrial, nas mesmas condições descritas acima. As curvas de tingimento estão representadas na figura 2. Os tingimentos foram realizados com uma relação de banho (RB) 1:10, em canecos com capacidade para $50 \mathrm{~mL}$.

Figura 2: Curva de tingimento PES (a) e CO (b).

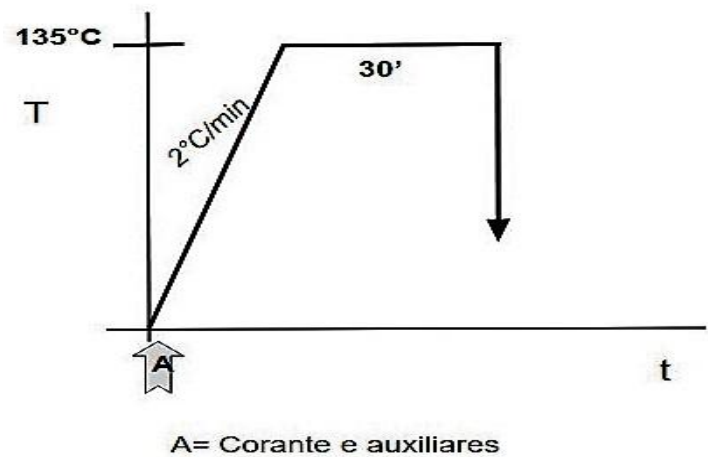

(a)

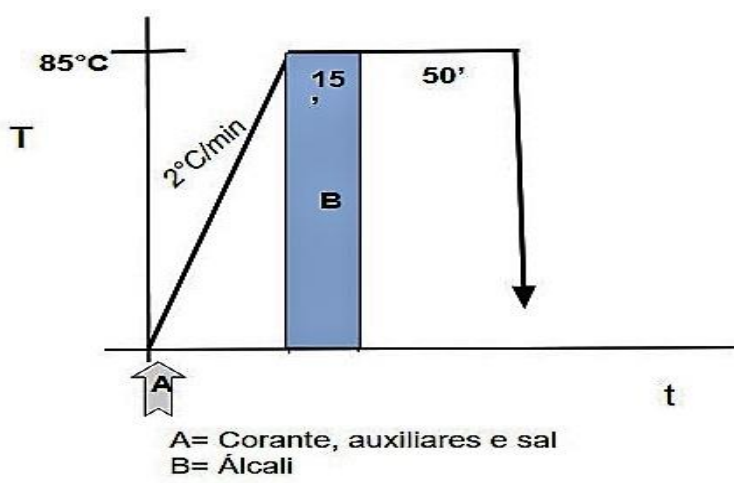

(b)

\subsection{Avaliação das propriedades tintoriais}

A determinação do esgotamento dos banhos de tingimentos foi realizada por espectrofotometria UV-Vis, no equipamento Espectrofotômetro UV-Vis Shimadzu UV-1800. Utilizou-se a equação 2 para o cálculo de percentual de esgotamento dos banhos de tingimento, ou seja, o percentual de corante que migrou do banho para o tecido.

$$
E(\%)=\frac{A b s \cdot(\lambda \max ) \mathrm{A}-\mathrm{Abs} \cdot(\lambda \max ) \mathrm{P}}{A b s \cdot(\lambda \max ) \mathrm{A}} \times 100
$$

Onde: Abs.( $\lambda \max ) A=$ absorbância antes do tingimento (591nm (PES) e 512nm (CO)).

Abs. $(\lambda \max ) \mathrm{P}=$ absorbância após tingimento (591nm (PES) e 512nm (CO)). 
A intensidade colorística (K/S) (equação 3), a força colorística relativa FR (\%) (equação 4), bem como a diferença de cor residual (DE) (equação 5) foram determinadas ao comparar as amostras tintas com a amostra padrão. Estes parâmetros foram determinados utilizando um espectrofotômetro de remissão Optronik (Mathis).

$$
\mathrm{K} / \mathrm{S}=\frac{(1-R)^{2}}{2 R}
$$

Onde: K corresponde à absorção de luz pelo corante, $\mathrm{S}$ à medida da difusão da luz pelo substrato e $\mathrm{R}$ ao valor da remissão.

$$
\begin{aligned}
& F R(\%)=\frac{\text { Força colorística amostra }}{\text { Força colorística padrão }} \times 100 \\
& D E=\sqrt{(D H)^{2}+(D C)^{2}+(D L)^{2}}
\end{aligned}
$$

Onde: $\mathrm{DH}=$ desvio de tonalidade $; \mathrm{DC}=$ desvio de pureza $; \mathrm{DL}=$ desvio de claridade.

\subsection{Ensaios de Solidez}

As análises de solidez à fricção (seco e úmido) foram realizadas no aparelho Crockmeter, conforme norma técnica ABNT NBR ISO 105 - X12:2007 [19]. Avaliou-se também a solidez à lavagem, conforme norma técnica ABNT NBR ISO 105-C 06:2006 [20].

Para avaliação da solidez utilizou-se a escala de cinza, conforme normas técnicas ABNT NBR ISO 105A02:2006: escala cinza para avaliação da alteração da cor [21]. E, ABNT NBR ISO 105-A03:2006: Escala cinza para avaliação da transferência de cor [22], que varia de 1 a 5 sendo 5 a nota máxima, ou seja, quando não há alteração da cor.

\section{RESULTADOS E DISCUSSÃO}

\subsection{Determinação da eficiência do tratamento}

Para a realização deste estudo foram utilizados dois lotes de corante Disperso Rubi Colorpes S-EGFL 250\%, os lotes não apresentaram o mesmo comprimento de onda máximo, sendo $477 \mathrm{~nm}$ e $498 \mathrm{~nm}$, como pode ser visto na figura 3. Observa-se nos espectros abaixo, um intenso decaimento de banda de absorção, para ambos os lotes de corantes, relacionado a elevada remoção do corante das soluções.

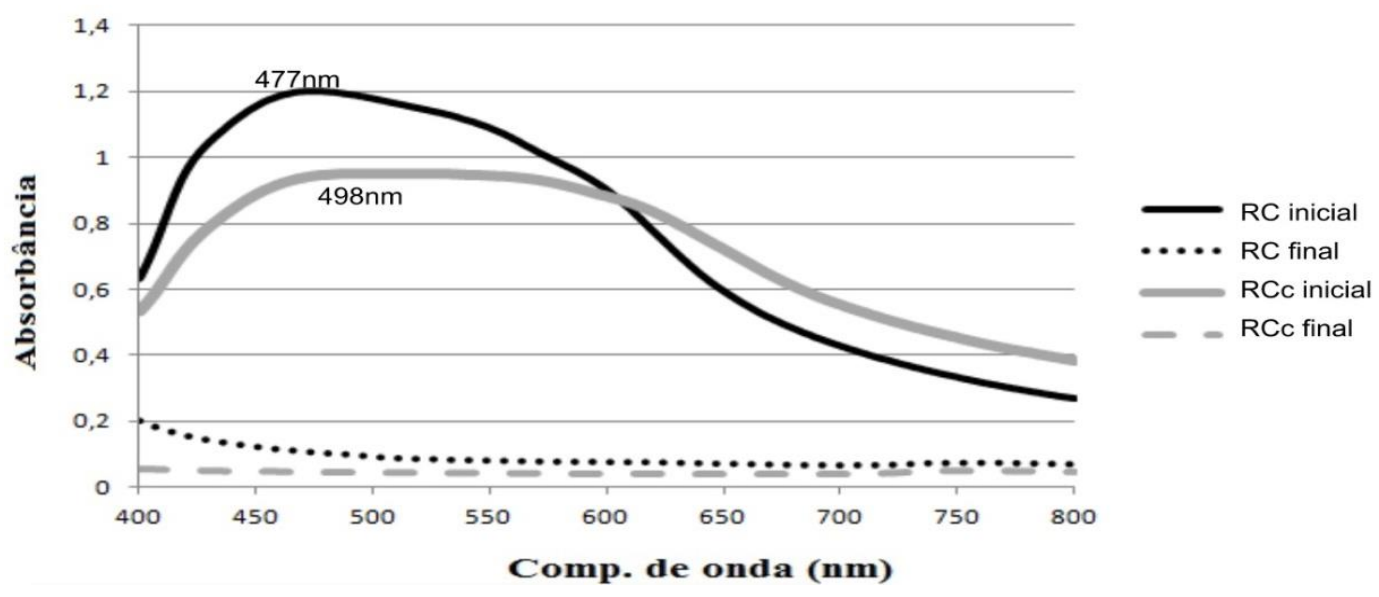

Figura 3: Espectro na região do visível das soluções de corante Disperso Rubi Colorpes S-EGFL 250\%, antes e após o tratamento por adsorção. 
Com base nos dados obtidos a eficiência do tratamento com resíduo natural (RC) foi de 91,26\%, já utilizando o resíduo calcinado (RCc) a eficiência chegou a 95,38\%, ocorrendo um ganho de 4\% de remoção utilizando $50 \%(\mathrm{~m} / \mathrm{v})$ a menos de adsorvente. Enquanto a figura 3 apresenta a eficiência através dos espectros, pela curva de absorbância, na figura 4 a remoção de cor também pode ser observada visualmente.

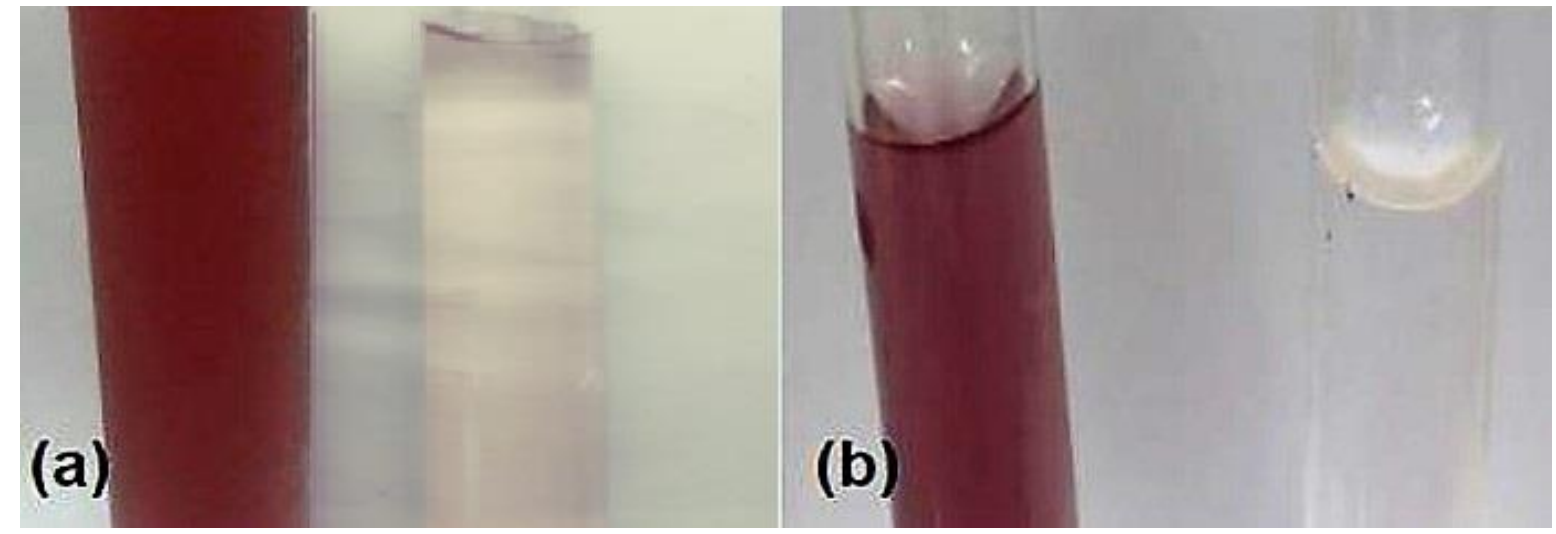

Figura 4: Remoção de cor de corante: (a) utilizando RC, (b) utilizando RCc.

Na literatura encontram-se valores similares para outros métodos de tratamento ou outros adsorventes, como por exemplo, BERTOLDI [23] que obteve em sua pesquisa uma eficiência entre $75 \%$ e $96 \%$ para a remoção de corantes reativos (Procion Amarelo H-EXL e Procion Azul H-EXL) em solução, ao utilizar cinza de casca de arroz como adsorvente. BRUNELLI e colaboradores [5] ao realizarem tratamento por oxidação foto eletrocatalítico em efluente contendo os corantes dispersos (Preto Dispersil e Azul Dispersil) obtiveram remoção de $100 \%$ após $2 \mathrm{~h}$ de tratamento. LUCENA e colaboradores [1] realizaram um estudo para remoção de corantes reativos (Amarelo Reativo GR, Azul R 160 \% Remazol e Verde Oliva B Colloisol Indranthren) da solução por adsorção com quitosana modificada com tioacetamida e obtiveram eficiência acima de $90 \%$. MELLO e colaboradores [4] realizaram um estudo utilizando a argila esmectita na remoção de corantes têxteis, que mostrou-se eficaz dependendo da classe do corante, com eficiência de 64,5\% para o corante ácido Nylosan Blue e 97,8 \% para o corante reativo Azul anil Op. SILVA e colaboradores [11] utilizaram cerâmica vermelha como adsorvente no tratamento de solução aquosa com corante Direct Blue obtendo remoção de cor que variou entre $98,2 \%$ a $99,5 \%$, dependendo das condições utilizadas no tratamento como: granulometria, tempo e massa do adsorvente. MENDES e colaboradores [10] utilizaram biomassa liofilizada de Saccharomyces cerevisiae como adsorvente para remoção do corante Direct Orange 2GL, a absorbância inicial no comprimento de onda máximo foi de 1,6 e após a adsorção com $1000 \mathrm{mg}$ de biomassa de S. cerevisiae a absorbância diminuiu para 0,063 , ou seja, houve uma remoção de corante de $96 \%$. Portanto, é válida a utilização do resíduo de clarificação de óleo vegetal, seja na forma natural ou calcinada, como adsorvente para remoção de corante têxtil (disperso) da solução, uma vez que apresentou eficiência semelhante aos estudos da literatura, sendo superior a $91 \%$.

\subsection{Determinação dos esgotamentos dos tingimentos}

A figura 5 apresenta os valores obtidos do esgotamento (\%) para os banhos de tingimento, utilizando água tratada com resíduo de clarificação natural (RC) e calcinado (RCc). Os valores variaram entre $80 \%$ e $92 \%$ para PES e $70 \%$ e $85 \%$ para CO, possibilitando até $100 \%$ de seu uso sem que haja interferência no esgotamento do banho de tingimento tanto para PES como para CO, bem como na uniformidade.

Nos processos das indústrias, os esgotamentos em média para tecidos de algodão variam de $65 \%$ a $90 \%$ dependendo do tipo de corante reativo (mono, bi, tri ou poli funcionais) e para PES acima de $90 \%$, sendo que para tecidos mescla de PES/CO (50/50) depende do processo de tingimento utilizado. No presente estudo o tingimento foi realizado separadamente, primeiro tingiu-se o poliéster e após trocar o banho tingiuse o algodão, desta forma os valores de esgotamento correspondem aos valores para cada fibra, portanto os resultados obtidos encontram-se dentro dos valores obtidos em escala industrial. 


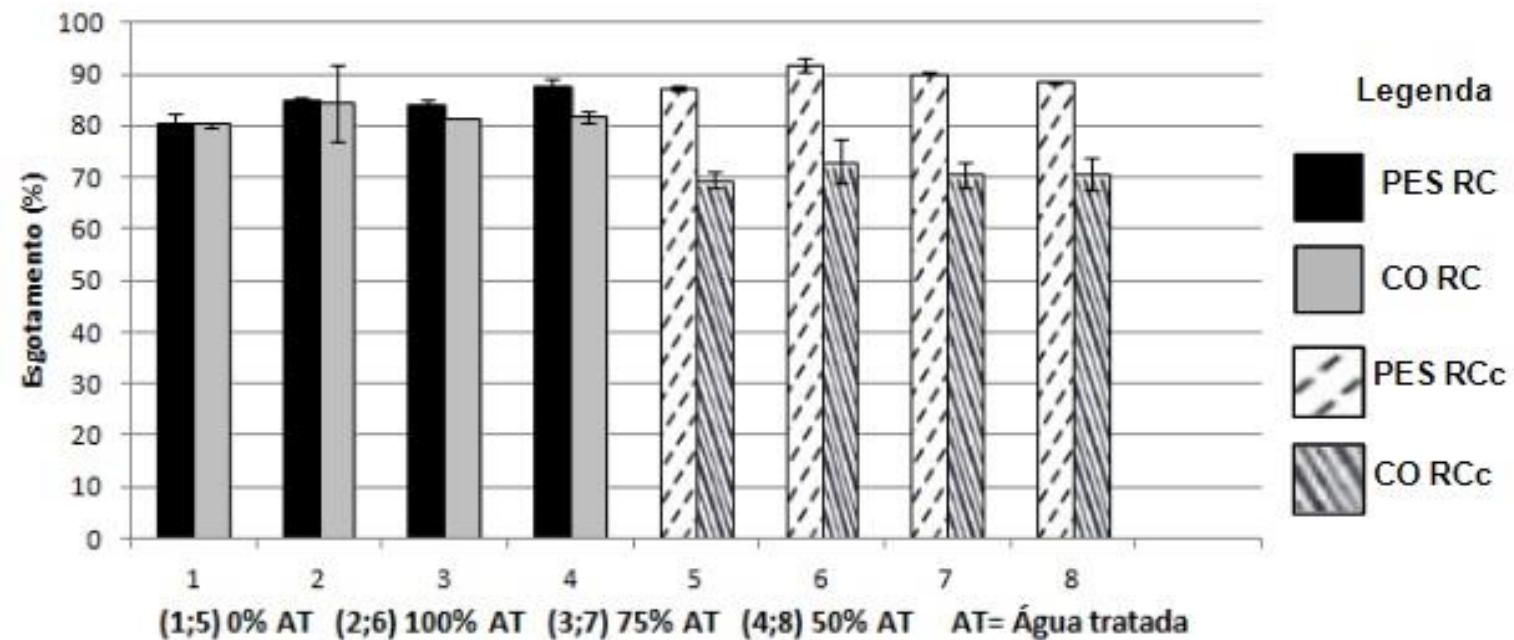

Figura 5: Esgotamento (\%) dos banhos de tingimento do tecido PES/CO (50/50) com água tratada com RC x RCc.

LUCAS e colaboradores [24] utilizaram o método fotoeletroquímico para tratar soluções de corante básicos, visando a reutilização. Ao reutilizar a solução tratada, previamente diluída nas proporções 90/10, $80 / 20$ e 70/30\% (v/v) efluente tratado/água destilada, em novos tingimentos de fibra acrílica obtiveram um esgotamento do banho de tingimento que variou de 97,7 a 99,6 \%. Utilizando o mesmo resíduo não calcinado empregado no presente estudo, MITTERSTEINER e colaboradores [15] realizaram um estudo de remoção de corante de uma solução de corante direto Preto 22, ao reutilizar esta solução tratada em novos tingimentos de algodão com corante reativo Blue 222, obtiveram esgotamento do banho de tingimento entre 88,1 \% a 94,8\%. MÜLLER [16] também utilizou água tratada com resíduo de clarificação de óleo vegetal natural e tratado termicamente $\left(180^{\circ} \mathrm{C}\right)$ para o tingimento de tecido $100 \%$ PES, com corante disperso Rubi, Marinho e Amarelo e obteve valores de esgotamento de banho de tingimento acima de $94 \%$. Este resultado comparado com o presente estudo indica que a presença da fibra de algodão no tecido de poliéster não interfere no esgotamento do tingimento com água tratada de solução de corante disperso.

\subsection{Determinação das propriedades tintoriais}

Os parâmetros intensidade colorística (K/S), força colorística relativa (FR \%) e diferença de cor residual (DE) são utilizados para avaliar a reprodutibilidade do tingimento do tecido malha PES/CO (50/50) com os corantes Vermelho Sidersperse Be2B e Vermelho Sidercron HC, na cor clara, comparando o tingimento padrão com os tingimentos realizados com água tratada com o resíduo natural e calcinado. Os valores dos parâmetros colorísticos para ambas as condições de tratamento de água estão apresentados na tabela 2.

Tabela 3: Resultados de K/S, FR e DE para tingimentos de PES/CO (50/50) com água tratada com RC e RCc.

\begin{tabular}{l|l|l|l|l}
\hline ÁGUA TRATADA (\%) & ADSORVENTE & $\mathbf{K}^{\mathbf{d p}}$ & $\mathbf{F R}(\%)^{\mathrm{dp}}$ & $\mathbf{D E}^{\mathrm{dp}}$ \\
\hline 0 & RC & $1,54^{0,03}$ & 100 & - \\
\hline 50 & RC & $1,55^{0,06}$ & $100,57^{3,64}$ & $0,65^{0,54}$ \\
\hline 75 & RC & $1,52^{0,03}$ & $98,56^{1,98}$ & $1,26^{0,13}$ \\
\hline 0 & RC & $1,4 /^{0,0}$ & $95,67^{0,19}$ & $1,27^{0,10}$ \\
\hline 50 & RCc & $1,24^{0,01}$ & 100 & - \\
\hline 75 & RCc & $1,17^{0,0}$ & $92,43^{0,19}$ & $0,33^{0,07}$ \\
\hline 100 & RCc & $1,15^{0,01}$ & $93,99^{0,60}$ & $0,22^{0,10}$ \\
\hline
\end{tabular}

$\mathrm{dp}=$ desvio padrão

Os valores de K/S foram próximos quando comparados ao padrão, tendo a maior variação de 0,09 unidades para o tingimento com $75 \%$ de água tratada com RCc. O parâmetro FR (\%) apresentou variação máxima de $7,2 \%$ para o tingimento com $50 \%$ de água tratada com RCc. 
Ao reutilizar efluente têxtil tratado por foto-fenton em tingimento de poliéster e poliamida, com corantes disperso e ácido respectivamente, BLANCO e colaboradores [25] obtiveram uma diferença de até 2,0 unidades nos valores de K/S quando comparado ao tingimento padrão (água utilizada na indústria), ficando dentro do aceito pela indústria em que foi realizado o estudo. No presente trabalho,o K/S não variou mais que 1,0 unidade, podendo-se dizer que este tratamento por adsorção foi mais eficiente para o reuso proposto.

O parâmetro decisivo para avaliação de um tingimento é a diferença de cor residual (DE), estando relacionado com a reprodutibilidade da cor, sendo que valores $\mathrm{DE} \leq 1,0$ são aceitos pela indústria, e quanto mais próximo de 0,3 , menor a detecção visual da diferença entre as amostras tintas.

Os resultados mostram que no tingimento com água tratada com resíduo natural é possível reutilizar até $50 \%$ de água tratada, já que foi a única condição onde o DE ficou abaixo de 1,0. Já para os tingimentos utilizando água tratada com RCc os resultados apresentaram uma melhora significativa, sendo que o maior valor para DE foi de 0,37 quando utilizado $100 \%$ de água tratada, valores estes que o olho humano não tem sensibilidade para perceber a diferença.

A diferença nos valores de DE pode ser explicado pela coloração ligeiramente amarelada da água tratada com resíduo natural (RC) que pode ter interferido neste tingimento, o que não foi observada na água tratada com resíduo calcinado. Essa tonalidade pode ser proveniente de pigmentos dos óleos naturais, de acordo com BOEY e colaboradores [26] os óleos vegetais apresentam banda de absorção em $269 \mathrm{~nm}$ e 446 $\mathrm{nm}$, que correspondem aos pigmentos naturais presentes nos óleos vegetais, provenientes do trienos conjugados e $\beta$ - carotenos, respectivamente. Neste trabalho encontrou-se uma absorção no comprimento de onda de $446 \mathrm{~nm}$ de 0,125 e 0,046 para as soluções tratadas com RC e RCc, respectivamente, o que explica a coloração ligeiramente amarelada da solução tratada com resíduo RC natural e não com o resíduo calcinado, na faixa de comprimento de onda utilizada neste estudo.

$\mathrm{Na}$ literatura encontram-se poucos estudos em que efluentes reais ou sintéticos foram tratados e reutilizados em novos tingimentos. No estudo realizado por SALA e colaboradores [27] ao reutilizarem efluente tratado com combinação entre tratamento eletroquímico e radiação UV, em novos tingimentos de algodão com corantes reativos, obtiveram DE entre 0,05 a 0,56, segundo autores é possível uma economia de água em até $70 \%$. BUSCIO e colaboradores [28] utilizaram tratamento combinado de homogeneização-decantação com ultrafiltração no tratamento de efluente, coletado em uma empresa na Espanha. Após o tratamento a água foi reutilizada em novos tingimentos de poliéster, na proporção 50/50 (v/v) água tratada/água destilada, com os corantes dispersos obtendo valores de DE entre 0,51 e 0,85 , resultando em uma economia de água de $50 \%$. HU e colaboradores [29] trataram banhos de tingimento contendo corante reativo blue 19 com ozônio combinado com aerogel de carbono mesoporoso e nanopartículas de óxido de cobalto. Após o tratamento a água foi reutilizada em novos tingimentos de algodão, obtendo DE entre 0,19 e 1,54. VREESE e VAN DER

BRUGGEN [30] obtiveram DE de 0,25 e 0,09 para tingimentos com cores clara e escura, respectivamente, ao tingir fios de poliéster utilizando efluente têxtil tratado por nanofiltração. Ao reutilizar a solução de corante reativo tratada por adsorção com cinza de casca de arroz, em novos tingimentos de algodão com corantes reativos Yellow 145 e Blue 222 (monocromia e bicromia) e corante direto Black 22 (monocromia)

WILHELM e BARCELLOS [7] obtiveram valores de DE que variaram entre 0,18 a 0,45 e 0,45 a 0,52 para os tingimentos de algodão em monocromia e bicromia com corante reativo, respectivamente, já para monocromia com corante direto os valores de DE variaram de 0,56 a 1,02, esses valores correspondem a uma economia de água de até $100 \%$. Ainda para tingimentos de algodão, MITTERSTEINER e colaboradores [15] ao reutilizarem uma solução de corante direto Preto 22 tratada por adsorção com resíduo de clarificação (RC), em novos tingimentos de algodão com corante reativo Blue 222, obtiveram um DE que variou de 0,24 a 2,31 dependendo da condição do adsorvente utilizado, para as condições em que o adsorvente foi previamente tratado termicamente (em estufa $\sim 180^{\circ} \mathrm{C}$ ) os valores de DE foram satisfatórios (DE $\left.<1,0\right)$ possibilitando até $100 \%$ de reuso da solução tratada.

\subsection{Avaliação dos ensaios de solidez}

As notas para a solidez são atribuídas através de uma escala de cinza sendo a nota máxima 5 e a nota mínima 1. Essas notas de solidez ajudam a atestar a qualidade dos artigos têxteis em relação ao desbotamento e manchamento da cor, quanto à lavagem e à fricção de uma peça em outra, por exemplo.

Os resultados para os ensaios de solidez estão apresentados na tabela 3, para o tingimento utilizando água tratada com resíduo natural (RC) e calcinado (RCc). Como pode ser observado os resultados para os testes de solidez foram bastantes satisfatórios, pois suas notas foram entre 4 e 5, ou seja, não há migração do corante, perceptível. Na literatura encontram-se poucos estudos sobre reutilização de água com avaliação da solidez. Até a elaboração deste artigo não foram encontradas pesquisas abordando a avaliação de solidez em 
tecidos PES/CO, para fins comparativos neste estudo, e poucos estudos com outros tipos de fibras.

Tabela 4: Solidez à fricção e a lavagem para tingimentos de PES/CO (50/50) com água tratada com RC e RCc.

\begin{tabular}{|c|c|c|c|c|c|c|c|c|}
\hline \multirow{2}{*}{$\begin{array}{l}\text { ÁGUA TRATA- } \\
\text { DA (\%) }\end{array}$} & \multirow[t]{2}{*}{ ADSORVENTE } & \multicolumn{2}{|c|}{ FRICÇÃO SECO } & \multicolumn{2}{|c|}{ FRICÇÃO ÚMIDO } & \multicolumn{2}{|c|}{ LAVAGEM } & \multirow{2}{*}{$\begin{array}{l}\text { ALTERAÇÃO } \\
\text { DE COR }\end{array}$} \\
\hline & & $\mathrm{CO}$ & PES & $\mathrm{CO}$ & PES & $\mathrm{CO}$ & PES & \\
\hline 0 & $\mathrm{RC}$ & 5 & 5 & $4 / 5$ & 5 & 5 & $4 / 5$ & 5 \\
\hline 50 & $\mathrm{RC}$ & 5 & 5 & $4 / 5$ & 5 & 5 & $4 / 5$ & $4 / 5$ \\
\hline 75 & $\mathrm{RC}$ & 5 & 5 & $4 / 5$ & 5 & 5 & $4 / 5$ & $4 / 5$ \\
\hline 100 & $\mathrm{RC}$ & 5 & 5 & $4 / 5$ & $4 / 5$ & 5 & $4 / 5$ & $4 / 5$ \\
\hline 0 & $\mathrm{RCc}$ & 5 & 5 & 5 & 5 & 5 & $4 / 5$ & 5 \\
\hline 50 & $\mathrm{RCc}$ & 5 & 5 & $4 / 5$ & 5 & 5 & $4 / 5$ & 5 \\
\hline 75 & RCc & 5 & 5 & $4 / 5$ & 5 & 5 & 5 & 5 \\
\hline 100 & $\mathrm{RCc}$ & 5 & 5 & $4 / 5$ & 5 & 5 & 5 & 5 \\
\hline
\end{tabular}

RIERA-TORRES e colaboradores [31] reutilizaram soluções de corante reativos tratadas com processo eletroquímico, em novos tingimentos de algodão e obtiveram notas para solidez à fricção entre 4 e 5 . WILHELM e BARCELLOS [7] ao utilizar solução de corante reativo tratada com cinza de casca de arroz em tingimentos de algodão, obtiveram notas de solidez à lavagem e à fricção que variaram entre 3/4 e 5. Ao utilizar água tratada por nanofiltração, em tingimentos de poliéster utilizando corantes claros e escuros, VREESE e VAN DER BRUGGEN [30] obtiveram notas de solidez da cor à lavagem doméstica e à fricção que variaram entre $4 / 5$ e 5.

MÜLLER [16] ao utilizar soluções tratadas com o mesmo resíduo (RC) utilizado no presente trabalho, em novos tingimentos de poliéster com corante disperso, obteve notas que predominaram entre 4,0 e 5,0, exceto para a solidez à lavagem à $40{ }^{\circ} \mathrm{C}$ em que alguns corantes apresentaram notas entre 3 e $3 / 4$ para o testemunho de PES. JEYARAJ e colaboradores [3] realizaram um estudo afim de comparar o tingimento de tecido $100 \%$ seda com um tecido mescla Seda/PES/Lyocell (50/25/25), utilizando corantes naturais e sintéticos. Os autores obtiveram notas de solidez à lavação entre 3-4, e valores ainda menores para a solidez à fricção, sendo 2-3 para a fricção a seco e 1-2 a úmido, esses valores indicam que houve migração do corante, o que não acontece no caso da mistura de fibra (PES/CO) utilizada nesse estudo, onde obteve-se notas entre 4-5. Portanto, os resultados dos ensaios de solidez obtidos no presente trabalho, sinalizam também para o uso de até $100 \%$ da água tratada, uma vez que não houve migração do corante.

\section{CONCLUSÃO}

O tratamento por adsorção com resíduo de clarificação de óleos vegetais, tanto na forma natural, quanto na forma calcinada, mostrou-se eficiente apresentando alto índice de remoção do corante Disperso Rubi Colorpes S-EGFL $250 \%$ da solução, sendo superior a $90 \%$. As propriedades tintoriais também apresentaram resultados satisfatórios, os percentuais de esgotamento dos banhos de tingimento encontram-se dentro do praticado na indústria, com valores que variaram entre $80 \%$ e $92 \%$ para poliéster e $70 \%$ e $85 \%$ para algodão. A intensidade colorística (K/S) e a força colorística relativa (FR) apresentaram valores bem próximos ao tingimento padrão, com variação máxima de 0,09 unidades para o K/S e 7,2 \% para FR. O parâmetro diferença de cor residual (DE), variou entre 0,65 a 1,27 para o tingimento utilizando água tratada com resíduo natural (RC) sendo possível utilizar até $50 \%$ de água tratada, já para os tingimentos utilizando água tratada com resíduo calcinado $(\mathrm{RCc}$ ) obteve-se $\mathrm{DE} 0,22$ a 0,37 , podendo assim reutilizar até $100 \%$ de água tratada, mesmo para cores claras. Os testes de solidez à fricção e à lavagem obtiveram notas que variaram entre $4 / 5$ e 5 , indicando que não houve migração do corante.

Com base nos resultados obtidos neste trabalho pode-se afirmar que este tratamento gerou um reaproveitamento de até $100 \%$ de água tratada com resíduo calcinado $(\mathrm{RCc})$ e até $50 \%$ de água tratada com resíduo natural (RC), podendo ser maior esta economia quando forem realizados tingimentos com cores escuras.

\section{AGRADECIMENTOS}

À BUNGE, pela doação do resíduo. À Colorquímica e Siderquímica pela doação dos corantes. À Trama Z pelo apoio. À FURB por possibilitar a realização desta pesquisa, para o trabalho de conclusão do curso. 


\section{BIBLIOGRAFIA}

[1] LUCENA, G. L., SILVA, A. G., HONÓRIO, L. M. C., et al. "Remoção de corantes têxteis a partir de soluções aquosas por quitosana modificada com tioacetamida”, Ambi-Agua, v. 8, n. 1, pp. 144-154, Mar. 2013.

[2] SINTEX. Indústria Têxtil de Santa Catarina, Perspectivas e Desafios para o Crescimento. 2015. Disponível em:<http://www.sintex.org.br/arquivos/249_ap_sintex2015_final.pdf> Acesso em:30/08/2016

[3] JEYARAJ, J. M., ARUMUGAM, M., KULANDAIAPPAN, V., "A study on the functional properties of silk and polyester / lyocell mixed fabric", Revista Matéria, v. 20, n. 4, pp.924-925, 2015.

[4] MELLO, V. F. B., GAMA, J., FERREIRA, J. M., et al. "Estudo e caracterização de propriedades da argila esmectita na remoção de corantes têxteis”, Revista Matéria, v. 18, n. 04, pp. 1467 - 1482, 2013.

[5] BRUNELLI, T. F. T., GUARALDO, T. T., PASCHOAL F. M. M., et al. "Degradação fotoeletroquímica de corantes dispersos em efluente têxtil utilizando fotoanodos de Ti/TiO2", Química Nova, v. 32, n. 31, pp. 67-71, 2009.

[6] KIM, E., KIM, J. “An Avant-Garde collection Inspired by the Global Water Crisis: Recycling Waste to Aesthetic Garments", Journal of Textile Engineering \& Fashion Technology, v.4 , n.1 , pp. 80- 100, 2018.

[7] WILHELM, F., BARCELLOS, I. O. "Reuso em tingimentos de malha de algodão de uma solução de bicromia de corantes reativos tratadas com bioadsorvente", Química Têxtil, v. XL, n. 124, pp.28-36, Set. 2016.

[8] MARIN, S. L. A. "Remoção dos corantes têxteis C.I. reactive blue 203 e C.I. reactivered 195 mediante o uso de bagaço de maçã como adsorvente”, Dissertação de M. Sc., UFTPR, Pato Branco, PR, Brasil, 2015.

[9] PATIAS, S. G. O., SÁVIO, J., COSTELLI, M. C., et al. "Obtenção de carvão adsorvente oriundo da casca de pequi (Caryocar brasiliense) e sua aplicação no tratamento de efluentes da indústria têxtil através do processo de adsorção", Revista Eletrônica em Gestão, Educação e Tecnologia Ambiental (REGET/UFSM), v.19, n. 2, pp. 1482-1492, mai./ago. 2015.

[10] MENDES, C. R., DILARRI, G., PELEGRINI, R. T. “Aplicação da biomassa Saccharomyces cerevisiae como agente adsorvente do corante Direct Orange 2GL e os possíveis mecanismos de interações adsorbato/adsorvente", Revista Matéria, v.20, n.4, pp. 898 - 908, 2015.

[11] SILVA, A.B.C., ANDRADE R. M.F., FREIRE, F. B., et al. "Análise da utilização de cerâmica vermelha como adsorvente na remoção do corante têxtil Direct Blue de uma solução aquosa." Revista Matéria, v.22, n.3, 2017.

[12] DUARTE-NETO, J. F., MENEZES, R. R., NEVES, G. A. "Processo adsortivo de corantes por argilas esmectíticas do município de Boa Vista - Paraíba." Revista Eletrônica de Materiais e Processos, v. 9, n. 3, pp. 151-156, 2014.

[13] MALLAMPATI, R., TAN, K. S., VALIYAVEETTIL, S. "Utilization of corn fibers and luffa peels for extraction of pollutants from water", International Biodeterioration \& Biodegradation, v.103, pp. 8-15, 2015.

[14] KYZAS, G Z., LAZARIDIS, N. K., MITROPOULOS, A. CH. "Removal of dyes from aqueous solutions with untreated coffee residues as potential low-cost adsorbents: Equilibrium, reuse and thermodynamic approach.” Chemical Engineering Journal, v. 189-190, pp.148-159, 2012.

[15] MITTERSTEINER, M., SCHMITZ, F., BARCELLOS, I. O. "Reuse of dye-colored water post-treated with industrial water: Its adsorption kinects and evaluation of method efficiency in cotton fabric dyeing." Journal of Water Process Engineering. v.17, pp.181-187. 2017.

[16] MÜLLER, G. C. "Valorização de reuso de soluções coloridas tratadas com resíduo industrial como adsorvente em tingimentos de tecidos de poliéster/elastano.” Dissertação de M. Sc, FURB, Blumenau, SC, Brasil, 2017.

[17] Estatística mensal do complexo $\quad$ de $\quad$ soja http://www.abiove.org.br/site/_FILES/Portugues/07112017155647-2017-11-07__quadro_de_oferta_e_demanda.pdf .Acessada em Junho 2017.

[18] LUNELLI, S. A. "Estudo da regeneração térmica e da estimativa de custos de investimentos de uma unidade de recuperação”, Dissertação de M.Sc, FURB, Blumenau, SC, Brasil, 2015.

[19] ASSOCIAÇÃO DE NORMAS TÉCNICAS. ABNT NBR ISO 105 - X12:2007: Têxteis - Ensaios de solidez da cor. Parte X12: Solidez a fricção. Rio de Janeiro: ABNT, 2007

[20] . ABNT NBR ISO 105-C 06:2006: Têxteis - Ensaios de solidez da cor. Parte C 06: solidez da cor a lavagem doméstica e comercial. Rio de Janeiro: ABNT, 2006 
[21] ABNT NBR ISO 105-A02:2006: Têxteis - Ensaios de solidez da cor: escala cinza para avaliação da alteração da cor. Rio de Janeiro: ABNT, 2006

[22]__ _ ABNT NBR ISO 105-A03:2006: Têxteis - Ensaios de solidez da cor: Escala cinza para avaliação da transferência de cor. Rio de Janeiro: ABNT, 2006

[23] BERTOLDI, J. F. "Estudo cinético e das isotermas de adsorção das soluções de bicromia dos corantes reativos amarelo e azul procion H-EXL em cinza de casca de arroz", Dissertação de M. Sc., FURB, Blumenau, SC, Brasil, 2015.

[24] LUCAS, M., JEREMIAS, P. F. P. T., ANDREAUS, J., et al. "Reutilização de efluente de tingimentos de fibras acrílicas pós tratamento fotoeletroquímico", Química Nova, v.31, n.6, pp. 1362-1363, Ago. 2008.

[25] BLANCO, J., TORRADES, F., MORÓN, M., et al. "Photo-fenton and sequencing batch reactor coupled to photo-fenton processes for textile wastewater reclamation: Feasibility of reuse in dyeing processes", Chemical Engineering Journal, v. 240, pp. 469-475, 2014.

[26] BOEY, P.-L., GANESAN, S., MANIAM, G. P. "Regeneration and reutilization of OilLaden spent bleaching clay via in situ transesterification and calcination", J Am Oil Chem Soc, v. 88, pp.1247- 1253, Feb.2011.

[27] SALA, M., LÓPEZ-GRIMAU, V., GUTIÉRREZ-BOUZÁN, C. "Photo-electrochemical treatment of reactive dyes in wastewater and reuse of the effluent: Method Optimization", Materials, v. 7, pp. 7349-7365, Nov. 2014.

[28] BUSCIO, V. MARÍN, M. J. CRESPI, M., et al. "Reuse of textile wastewater after homogenizationdecantation treatment coupled to PVDF ultrafiltration membranes", Chemical Engineering Journal, n. 265, pp. 122-128, 2015.

[29] HU, E., SHANG, S., TAO, X-m., et al., "Regeneration and reuse of highly polluting textile dyeing effluents through catalytic ozonation with carbon aerogel catalysts", Journal of Cleaner Production, v. 137, pp.1055-1065, 2016.

[30] VREESE, I., VAN DER BRUGGEN, B. "Cotton and polyester dyeing using nanofiltered wastewater", Dyes and Pigments, n. 74, pp. 313-319, 2007.

[31] RIERA-TORRES, M., GUTIÉRREZ-BOUZÁN, M. C., MORELL, J.V., et al., "Influence of electrochemical pre-treatment in dyeing wastewater reuse for five reactive dyes", Textile Research Journal, v. 81, n. 18, pp. 1926- 1939, 2011.

\section{ORCID}

Taciane Samira Dalla Cort

https://orcid.org/0000-0003-3328-7696

Ivonete Oliveira Barcellos

https://orcid.org/0000-0002-8725-5027 